Revista Brasileira de Agricultura Irrigada v.4, nº. 3, p.166-171, 2010

ISSN 1982-7679 (On-line)

Fortaleza, CE, INOVAGRI - http://www.inovagri.org.br

Protocolo 014.186 - 10/03/2010 Aprovado em 11/06/2010

\title{
DESENVOLVIMENTO INICIAL DO CLONE BRS 275 DE CAJUEIRO SOB IRRIGAÇÃO COM DIFERENTES NÍVEIS SALINOS.
}

\author{
Alan Bernard Oliveira de Sousa ${ }^{1}$; Marlos Alves Bezerra ${ }^{2}$; Fábio Costa Farias ${ }^{3}$; \\ ${ }^{1}$ Mestrando em Irrigação e drenagem, Depto. Engenharia Agrícola, UFC, Fortaleza-CE, e-mail:alan2b@ gmail.com. \\ ${ }^{2}$ Pesquisador, Embrapa Agroindústria Tropical, Fortaleza-CE. \\ ${ }^{3}$ Mestre em Fitotecnia, UFC, Fortaleza-CE,
}

\section{RESUMO}

No Brasil, a maioria dos pomares de cajueiro está localizada no trópico semi-árido, onde a água é escassa e apresenta problemas de salinidade. Dessa forma, este trabalho teve por objetivo avaliar o efeito da salinidade no desenvolvimento inicial de mudas de cajueiro BRS 275. O Experimento foi conduzido em casa de vegetação da Embrapa Agroindústria Tropical Fortaleza CE, Brasil. Sementes do clone BRS 275 foram semeadas em tubetes contendo vermiculita. Os tratamentos utilizados foram soluções salinas ajustadas para as condutividades elétricas (CEa) de 3, 6, 9 e $12 \mathrm{dS} \mathrm{m}^{-1}$, sendo utilizado como testemunha irrigação com água destilada $\left(0 \mathrm{dS} \mathrm{m}^{-1}\right)$. O delineamento experimental foi o inteiramente casualizado, com quatro repetições e cinco plântulas por parcela. As variáveis avaliadas foram: altura da plântula (AP), diâmetro da plântula (DP), número de folhas (NF), área foliar (AF), matéria seca das folhas (MSF), matéria seca do caule (MSC), matéria seca da raiz (MSR) e condutividade do substrato (CEs), obtidas 15 dias após a emergência. A irrigação com água salina evidenciou efeito linear negativo para as variáveis das plântulas, exceto para DP que não apresentou significância e MSC que apresentou efeito quadrático. Podendo-se observar que com o aumento da concentração salina ocorreu redução no desenvolvimento inicial das plântulas de cajueiro, clone BRS 275.

Palavras-chave: Irrigação; Salinidade; Anacardium occidentale.

\section{ABSTRACT \\ DEVELOPMENT OF YOUNG CASHEW “CLONE BRS 275” UNDER IRRIGATION WITH DIFFERENT SALINE LEVELS}

Most cashew orchards in Brazil is located in semi-arid tropics, where water is scarce and has salinity problems. Based on this fact, this study aimed to evaluate the effect of salinity on early development of seedlings of cashew BRS 275. The experiment was conducted in a greenhouse at Embrapa Fortaleza - CE, Brazil. Seeds of BRS 275 were sown in containers containing vermiculite. The treatments were saline solutions with different electrical conductivity 


\section{DESENVOLVIMENTO INICIAL DO CLONE BRS 275 DE CAJUEIRO SOB IRRIGAÇÃO COM DIFERENTES NÍVEIS SALINOS.}

(ECw) 3, 6, 9 and $12 \mathrm{dS} \mathrm{m}^{-1}$, being the distilled water used as control $\left(0 \mathrm{dS} \mathrm{m}^{-1}\right)$. The experiment was a completely randomized design with four replications of five seedlings per plot. Evaluated it seedling height (AP) diameter of the seedling (DP), number of leaves (NF), leaf area (AF), dry matter of leaf (MSF), dry matter of stem (MSC), dry matter of root (MSR) and the substrate conductivity (CEs), obtained 15 days after emergence of seedling. The irrigation with saline water showed a linear effect for all variables of plantets, except for DP that showed no significance and the MSC had a quadratic effect. The increasing salt concentration reduced the early development of seedlings of cashew, clone BRS 275.

KEYWORDS: Irrigation; salinity; Anacardium occidentale.

\section{INTRODUÇÃO}

Dentre as espécies frutíferas cultivadas no Nordeste brasileiro, destaca-se o cajueiro, tanto pelo potencial de exportação de suas castanhas quanto pela área de produção, chegando a mais de 730.000 ha plantados onde mais de 380.00 ha encontra-se no estado do Ceará (IBGE, 2007).

Grande parte destes pomares foi propagada por sementes e são cultivados sob regime de sequeiro (Barros et al., 2002; 2004), embora nos últimos anos a prática de irrigação vêm se tornando fundamental para o estabelecimento de novos pomares mais produtivos (Cavalcanti Junior \& Chaves, 2001). A maioria dos pomares de cajueiro no Brasil está localizada no trópico semi-árido, onde a água é escassa e apresenta problemas de salinidade (Gheyi, 2000), o que obriga desde os viveiristas até aqueles que irrigam as plantas a utilizarem água salina ou de qualidade.

Em geral, a salinidade inibe $\mathrm{o}$ crescimento das plantas, em função dos efeitos osmóticos e tóxicos dos íons (Munns, 2002). Dentre os processos fisiológicos afetados pelo estresse salino, destacam-se a assimilação do $\mathrm{CO}_{2}$ e a síntese de proteínas, as quais limitam a capacidade produtiva das plantas. No caso da produção de mudas, esse efeito é mais pronunciado, uma vez que nessa fase as plântulas estão mais susceptíveis aos efeitos do sal. Em cajueiro anão precoce estudos evidenciam que a porcentagem de germinação só é afetada em níveis elevados de sal, no entanto o tempo médio de emergência das plântulas de cajueiro é afetado atrasando assim a emergência dessas plântulas (Bezerra et al., 2002; Carneiro et al., 2002). Podendo-se inferir que o cajueiro anão precoce é mais tolerante durante a germinação que durante as fases posteriores do desenvolvimento de plântulas (Bezerra et. al. 2007).

Dessa forma, este trabalho teve por objetivo avaliar o efeito da irrigação com diferentes concentrações salinas nos quinze primeiros dias de desenvolvimento de mudas de cajueiro (clone BRS 275).

\section{MATERIAL E MÉTODOS}

O Experimento foi conduzido em casa de vegetação da Embrapa Agroindústria Tropical Fortaleza - CE, Brasil. Sementes oriundas do clone BRS 275 foram semeadas em tubetes de polipropileno, contendo 288 $\mathrm{cm}^{3}$ de vermiculita.

A partir da semeadura, iniciou-se a aplicação dos tratamentos, que consistiu da aplicação a cada dois dias de $50 \mathrm{~mL}$ de solução salina, de acordo com o tratamento estabelecido. Os tratamentos utilizados foram soluções salinas ajustadas para as condutividades elétricas (CEa) de 3, 6, 9 e 


\section{DESENVOLVIMENTO INICIAL DO CLONE BRS 275 DE CAJUEIRO SOB IRRIGAÇÃO COM DIFERENTES NÍVEIS SALINOS.}

$12 \mathrm{dS} \mathrm{m}^{-1}$, sendo utilizado como testemunha irrigação com água destilada.

As soluções salinas foram preparadas pela adição de diferentes quantidades de sais de $\mathrm{NaCl}, \mathrm{CaCl}_{2} \cdot 2 \mathrm{H}_{2} \mathrm{O}$ e $\mathrm{MgCl}_{2} \cdot 6 \mathrm{H}_{2} \mathrm{O}$, na proporção de $7: 2: 1$, obedecendo-se a relação entre CEa e a concentração $\left(\mathrm{mmol}_{\mathrm{c}} \mathrm{L}^{-1}=\mathrm{CE}\right.$ x 10), extraída de Rhoades et al. (1992).

Após 15 dias da emergência de 50\% das plântulas do tratamento controle, foram medidos as variáveis de crescimento: altura das plântulas (AP) com régua graduada, diâmetro do colo das plântulas (DP) com paquímetro digital, numero de folhas (NF) e área foliar (AF) utilizando-se um medidor tipo LI-3000, LiCor, Inc., Lincoln. Após a coleta, o material foi secado em estufa, para determinação da matéria seca foliar (MSF), matéria seca do caule (MSC) e matéria seca da raiz (MSR). Extraiu-se o extrato do substrato para determinação da condutividade elétrica (CEs).

O delineamento experimental foi $\mathrm{o}$ inteiramente casualizado, com quatro repetições (cinco plantas por parcela experimental). Os resultados foram submetidos à análise de variância e de regressão pelo programa SAEG, realizandose a comparação entre as concentrações salinas e as variáveis observadas.

\section{RESULTADOS E DISCUSSÃO}

A análise de variância (Tabela 1) permitiu verificar influências das diferentes concentrações salinas aplicadas para todas as variáveis, exceto diâmetro da plântula (DP). A salinidade da água de irrigação afetou negativamente o crescimento das plantas, sendo o efeito linear, com decréscimo relativo (comparado ao controle) para cada incremento unitário de CEa de 5\%, 3,2\% e $6,1 \%$ respectivamente para altura, numero de folhas e área foliar (Figuras 1A, 1C e 2D).
Os resultados foram semelhante aos obtidos por Carneiro et al. (2002), que trabalhando com genótipos de cajueiro anão precoce obtiveram para cada incremento unitário na CEa decréscimo de $8,49 \%$ para altura da planta e $14,82 \%$ para área foliar. Carneiro et al. (2007), observaram comportamento semelhante para AP e AF do clone CCP76 de cajueiro anão precoce em função da condutividade elétrica da água de irrigação.

A variável "diâmetro" das plântulas (DP) não apresentou significância e não evidenciou um efeito na análise de regressão (Figura 1B). Considerando que a salinidade provocou redução no crescimento do caule e não produziu efeito no diâmetro do mesmo, observa-se que a matéria seca do caule foi mais influenciada pela espessura do mesmo, uma vez que se existiu uma tendência de manutenção da MSC, independente do tratamento salino (Figura 1F).

As variáveis "massa seca da folha" e "massa seca da raiz" (MSF, MSR) foram afetadas negativamente $(\mathrm{p}<0,05)$ pela salinidade da água de irrigação. Os resultados decresceram linearmente (Figura $1 \mathrm{E}$ e $1 \mathrm{H})$ com o incremento da $\mathrm{CEa}$, na proporção de $6,3 \%$, e $6,7 \%$ respectivamente, para cada unidade de salinidade excedente à água utilizada no controle.

De acordo com Ayers \& Westcot (1999) como critério para escolha de uma cultura, quando se levam em conta problemas de salinidade, pode ser aceita uma diminuição no rendimento potencial de até $10 \%$, isto é, a salinidade máxima aceitável é aquela que permite produzir rendimento relativo mínimo de $90 \%$. Tomando por base a equação da massa seca das folhas pode-se verificar que na CEa de $1,58 \mathrm{dS}$ m-1 ocorre redução de $10 \%$ no rendimento potencial do clone de cajueiro comum BRS 275 podendo, então, ser considerado valor limite de 


\section{DESENVOLVIMENTO INICIAL DO CLONE BRS 275 DE CAJUEIRO SOB IRRIGAÇÃO COM DIFERENTES NÍVEIS SALINOS.}

salinidade para produção de mudas, até 15 dias após a emergência.

A condutividade elétrica do extrato do substrato apresentou efeito linear positivo e de cerca de 1,7 vezes o valor da condutividade da solução aplicada (Figura $1 \mathrm{H})$, o que mostra que parte dos íons salinos disponibilizados durante a irrigação se aderiram à vermiculita de forma cumulativa.
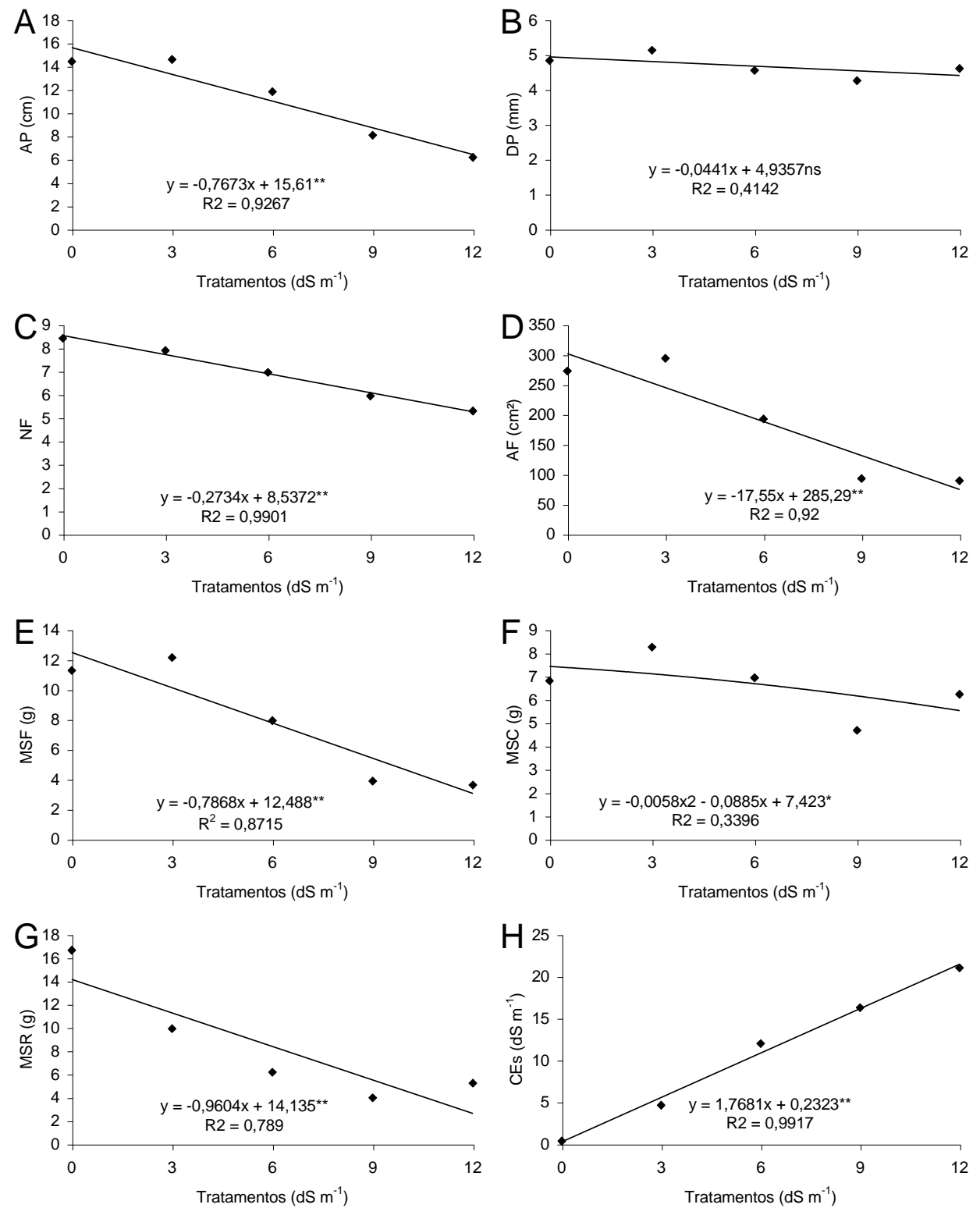

Figura 1. (A) Altura da plântula de cajueiro; (B) Diâmetro do colo das plântulas de cajueiro; (C) Número de folhas por plântulas de cajueiro; (D) Área foliar por plantulas; (E) Matéria seca das folhas por plântulas de cajueiro;(F) Matéria seca do caule por plântulas de cajueiro; (G) Matéria seca da raiz por plantula; (H) Condutividade elétrica do estrato do substrato de cajueiro BRS 275 , em função de diferentes concentrações salinas. ${ }^{* *}=$ significativo a $1 \%$ de probabilidade. 


\section{DESENVOLVIMENTO INICIAL DO CLONE BRS 275 DE CAJUEIRO SOB IRRIGAÇÃO COM DIFERENTES NÍVEIS SALINOS.}

Tabela 1. Resumo da análise de variância para altura da plântula (AP), diâmetro da plântula (DP), número de folhas (NF), área foliar (AF), matéria seca das folhas (MSF), matéria seca do caule (MSC), matéria seca da raiz (MSR) e condutividade do substrato (CEs) do clone BRS275 de cajueiro irrigado com águas de diferentes concentrações de sais.

Quadrados Médios

\begin{tabular}{lccccccccc}
\cline { 3 - 9 } F.V. & G.L. & AP & DP & NF & AF & MSF & MSC & MSR & CEs \\
\hline Tratamento & 4 & 57.18 & 0.426 & 6.533 & 29869 & 51.44 & 4.78 & 103.19 & 282.40 \\
Reg. Linear & 1 & $211.98^{* *}$ & $0.705 \mathrm{~ns}$ & $26.0^{* *}$ & $110947^{* *}$ & $192.1^{* *}$ & $6.53 \mathrm{~ns}$ & $312.73^{* *}$ & $1120^{* *}$ \\
Reg. Quad. & 1 & $7.51 \mathrm{~ns}$ & $0.040 \mathrm{~ns}$ & $0.008 \mathrm{~ns}$ & $15.52 \mathrm{~ns}$ & $0.04 \mathrm{~ns}$ & $0.00^{*}$ & $96.79^{*}$ & $1.43 \mathrm{~ns}$ \\
Reg. Cúbica & 1 & $9.18 \mathrm{~ns}$ & $0.921 \mathrm{~ns}$ & $0.100 \mathrm{~ns}$ & $7473 \mathrm{~ns}$ & $12.08 \mathrm{~ns}$ & $10.70 \mathrm{~ns}$ & $0.61 \mathrm{~ns}$ & $2.34 \mathrm{~ns}$ \\
Residuo & 15 & 5.38 & 0.255 & 1.06 & 4632 & 7.41 & 2.38 & 15.96 & 1.16 \\
\hline CV & $(\%)$ & 21 & 10.82 & 15 & 37 & 36 & 23 & 48 & 9.94
\end{tabular}

* e **significativo a 5 e $1 \%$ de probabilidade, respectivamente, ns não significativo.

\section{CONCLUSÃO}

$\mathrm{O}$ incremento da salinidade na água de irrigação inibiu o crescimento inicial das plântulas de cajueiro (clone BRS 275) em altura, número de folhas, área foliar, produção de fitomassa seca das folhas, caule e raiz, sendo o acúmulo de matéria seca mais sensível ao excesso de sais, com salinidade limiar de $1,58 \mathrm{dS} \mathrm{m}^{-1}$ na CEa.

\section{REFERÊNCIAS BIBLIOGRÁFICAS}

AYERS, R.S.; WESTCOT, D.W. A qualidade da água na agricultura. Campina Grande: UFPB, 1999. 153p. FAO. Estudos de Irrigação e Drenagem, 29.

BARROS, L.M.; CRISÓSTOMO, J.R.; PAIVA, W.O. DE; PAIVA, J.R. DE. Melhoramento genético do cajueiro. In: Silva, V.V. da. (ed.). Caju. O produtor pergunta, a Embrapa responde. Brasília: Embrapa-SPI, 2004. p.81-92.
BARROS, L.M.; PAIVA, J.R.; CAVALCANTI, J.J.V.; ARAÚJO, J.P.P. Cajueiro. In: BRUCKNER, C.H. (ed.). Melhoramento de Fruteiras Tropicais. Viçosa: Editora UFV, 2002. p.159-176.

BEZERRA M.A.; LACERDA C.F.; FILHO E.G.; ABREU C.E.B.; PRISCO J.T., Physiology of cashew plants grown under adverse conditions. Brazilian Journal Plant Physiology, v.19, n. 4, p. 449-461, 2007.

BEZERRA I.L., GHEYI H.R., FERNANDES P.D., SANTOS F.J.S., GURGEL M.T., NOBRE R.G. Germinação, formação de portaenxertos e enxertia de cajueiro anão-precoce sob estresse salino. Revista Brasileira de Ciências Agrárias, v.6, n.3, p.420-424, 2002.

CARNEIRO P.T.; CAVALCANTI, M.L.F.; BRITO, M. E. B.; GOMES, A.H.S.; FERNANDES, P.D.; GHEYI, H.R. Sensibilidade do cajueiro anão precoce ao estresse salino na pré-floração. Revista 


\section{DESENVOLVIMENTO INICIAL DO CLONE BRS 275 DE CAJUEIRO SOB IRRIGAÇÃO COM DIFERENTES NÍVEIS SALINOS.}

Brasileira de Ciências Agrárias, v.2, n.2, p.150-155, 2007.

CARNEIRO P.T.; FERNANDES P.D.; GHEYI, H.R.; SOARES F.A.L. Germinação e crescimento inicial de genótipos de cajueiro anão-precoce em condições de salinidade. Revista Brasileira de Engenharia Agrícola e Ambiental, v.6, n.2, p.199-206, 2002.

CAVALCANTI JUNIOR, A.T.; CHAVES, J.C.M. Produção de mudas de cajueiro. Fortaleza: Embrapa Agroindústria Tropical, 2001. Documentos No 42.
GHEYI, H.J. Problemas de salinidade na agricultura irrigada. In: Oliveira, T.S.; Assis Jr, R.N.; Romero, R.E.; Silva, J.R.C. (eds.). Agricultura, sustentabilidade e o semiárido. Fortaleza: DCS/UFC, 2000. p.329346.

IBGE - PESQUISA DA AGROPECUÁRIA MUNICIPAL. Instituto Brasileiro de Geografia e Estatística. Rio de Janeiro: IBGE, 2007. Disponível em < http://www.sidra.ibge.gov.br/> Acesso em; 13 abr. 2010.

MUNNS, R. Comparative physiology of salt and water stress. Plant Cell \& Environment, Oxford, v.25, n. 2, p.239250, 2002. 